\title{
Clindamycin Phosphate
}

National Cancer Institute

\section{Source}

National Cancer Institute. Clindamycin Phosphate. NCI Thesaurus. Code C47978.

The phosphate salt form of clindamycin, a semi-synthetic, chlorinated broad spectrum antibiotic produced by chemical modification of lincomycin. Clindamycin phosphate is used in topical preparations. 